\title{
Development and sensory evaluation of gluten free bakery products using quinoa (Chenopodium Quinoa) flour
}

\author{
Sukhmandeep Kaur* and Navjot Kaur \\ Department of Food and Nutrition, Punjab Agricultural University, Ludhiana (Punjab), INDIA \\ *Corresponding author: E-mail: sukhmani.deep20@gmail.com
}

Received: May 5, 2017; Revised received: June 24, 2017; Accepted: November 5, 2017

\begin{abstract}
Quinoa based gluten free bakery products were prepared by supplementing roasted quinoa flour in oats and rice flour at different substitution levels and were organoleptically evaluated using eight -point hedonic rating scale for sensory attributes by a semi - trained (including Professors and Assistant Professors not a professionally sensory panel) panel of 10 judges. Substitution of roasted quinoa flour at 5,10 and 15 percent levels showed significant difference $(p \leq 0.05)$ at 10 percent levels for all the products namely cookies, cakes, muffins, pies and tarts for overall acceptability. The products with 10 percent level of supplementation of roasted quinoa flour (10\%) with rice $(45 \%)$ and oats flour (45\%) were found to be highly acceptable and the scores for overall acceptability for cakes (7.54), cookies (7.46), muffins (7.32), pies (7.78) and tarts (7.56) were achieved. The pies with 10 percent level of supplementation of roasted quinoa flour were considered as best product by the judges in terms of all the sensory attributes such as appearance, colour, texture, flavour, taste and overall acceptability. It may be concluded that roasted quinoa flour can be utilized successfully upto 10 percent level to prepare gluten free bakery products with high nutritional value without imposing negative impact on sensory attributes which may prove a boon to celiac patients.
\end{abstract}

Keywords: Celiac disease, Quinoa, Organoleptic evaluation, Sensory attributes

\section{INTRODUCTION}

Quinoa (Chenopodium quinoa Willd.) has been cultivated in the Andean region (South American countries like Bolivia, Colombia, Ecuador and Peru) for several thousand years. It is being one of the main grain crops supplying highly nutritious food for the farmers (Jacobsen, 2003). Quinoa is known as treasure trove of nutrients with high protein content (16-18\%) with more than 37 percent of essential amino acids and a wide range of vitamins and minerals. Quinoa has a high biological value $(83 \%)$ because of its high concentration of proteins. It also contain a balanced set of essential amino acids such as methionine, cysteine and lysine and also making quinoa a good complement to legumes, which are limiting in these amino acids (Drzewiecki et al., 2003).

Quinoa protein is low in prolamines $(0.5-0.7 \%)$, which indicates that it is free of gluten and therefore nonallergenic. Quinoa contained total dietary fibre content of 13.4 percent consisting of 11.0 percent insoluble fibre and 2.4 percent soluble fibre (Ruales and Nair 1994). Quinoa contains 4.4-8.8 percent crude fat, with the essential fatty acids linoleic and linolenic acid accounting for 55 to 63 percent of the total fatty acids and has lipid lowering effect (Alvarez et al., 2010). Quinoa is an excellent example of "functional food" that aims at lowering the risk of various diseases such as coronary heart disease, atherosclerosis, cancer, diabetes and Alzheimer's disease. Quinoa and quinoa products are rich in not only macronutrients such as protein, polysaccharide and fats but also micronutrients such as polyphenols, vitamins and minerals. Polyphenols including phenolic acids, flavonoids and tannins make up the bioactive secondary plant metabolites that contribute to diverse physiological properties such as antimicrobial, antioxidant, anti-inflammatory, antitumor and anti-carcinogenic effects (Galvez et al., 2010)

Celiac disease (gluten-sensitive enteropathy) is a permanent intolerance to specific storage proteins in wheat (gliadin), barley (hordein) and rye (secalin) which are collectively called 'gluten'. Ingestion of gluten causes damage to the small intestinal mucosa by an autoimmune mechanism in genetically susceptible individuals. This can lead to a various symptoms and nutritional deficiencies (Rashid et al 2007). The treatment of celiac disease is a strict, life-long adherence to a gluten free diet. Ensuring that the foods and beverages are free of gluten remains a challenge for patients on such a diet. A gluten free diet is currently the only effective means of treating the individuals with celiac disease. Such a diet enables celiac patients to control their symptoms and avoid various complications associated with this condition. Rising demands for gluten free products parallels the apparent or real increase in 
celiac disease, non-celiac gluten sensitivity and gluten allergy. However, gluten removal results in major problems for bakers and currently many gluten free products available in the market are of low quality exhibiting poor mouth-feel and flavor. Thus, an increasing trend in research is focusing on the application of alternative grains potentially healthy to elaborate gluten free products. A promising area is the use of cereals (rice, corn and sorghum) minor cereals (fonio, teff, millet and job's tears) or pseudocereals such as amaranth, buckwheat and quinoa (Moreno et al., 2014).

Various products can be developed by using combination of flours prepared from nutritious grains at different levels because combination of these flours improves the nutritional quality and the acceptability of the products. By keeping in view all the properties of foods and rising demands for gluten free products for celiac patients, study was planned to develop some gluten free bakery products by using quinoa, rice and oats flours which will also be nutritionally balanced. The combination of these three flours will fulfill all the nutrient requirements of the individuals and also provide good mouth feel, taste and flavour to the products. Quinoa, rice and oats are potential healthy and high quality ingredients in gluten free products. The present study was carried out to study the development and sensory evaluation of gluten free bakery products using quinoa (Chenopodium Quinoa) flour.

\section{MATERIALS AND METHODS}

Procurement and processing of quinoa seeds: The samples of quinoa, rice flour and oats were procured from local market. Quinoa grains used for preparation of gluten free products were purchased from local market. The grains were cleaned properly to remove the impurities. After sorting, quinoa grains were roasted at $70^{\circ} \mathrm{C}$ for 3-4 minutes in an iron vessel on a low flame till aroma comes. After cooling, the grains were ground in grinder. The roasted grain powder was packed in air tight plastic container.

Chemical analysis: The flours were dried in oven at $\left(60 \pm 20^{\circ} \mathrm{C}\right)$ in petri dishes. The dried samples were stored in airtight polythene bags for chemical analysis. Proximate composition viz crude protein, crude fat, crude fibre, ash and minerals were analyzed by using standard methods (AOAC, 2000). For total minerals, samples were wet digested in hot plate using nitric acid and perchloric acid mixture in 5:1 ratio (v/v) and used for the determination of total amount of calcium, iron, magnesium and zinc by atomic absorption spectrophotometry (Lindsey and Norwell, 1969). Tryptophan estimation was done by (Concon, 1975). Methionine estimation was done by (Horn et al., 1946). Available Lysine was done by (Carpenter, 1960 modified by Booth, 1971).

Development of gluten free products: Quinoa based gluten free products such as cookies, cakes, muffins, pies and tarts were prepared using refined flour for control and for test samples, rice and oats flour (50$50 \%$ ) was supplemented with roasted quinoa flour at 5 , 10 and 15 percent levels in the Food laboratory of Food and Nutrition Department, College of Home Science, Punjab Agricultural University, Ludhiana.

Cookies: Fat $(60 \mathrm{~g})$ was rubbed on a clean surface. Flours (10g quinoa-45g rice-45g oats) were sifted and baking powder $(2 \mathrm{~g})$ was added gradually. Powdered sugar $(50 \mathrm{~g})$ was added in it. Smooth dough was made by using milk $(11 \mathrm{ml})$.Dough was rolled to $1 / 4$ inch thickness. Round shapes were cut and baked at $150^{\circ} \mathrm{C}$ for 20 minutes.

Cakes: Flours (10g quinoa-45g rice- $45 \mathrm{~g}$ oats) and baking powder $(2 \mathrm{~g})$ were sifted twice. Fat $(50 \mathrm{~g})$ and sugar $(100 \mathrm{~g})$ were creamed together till light and fluffy. Eggs $(100 \mathrm{~g})$ were beaten along with vanilla essence $(3 \mathrm{ml})$.Beaten eggs were added to the creamy mixture little by little mixing continuously. Flour was folded gently using cut-and-fold method. Milk was added to bring the mixture to dropping consistency. Mixture was poured in a greased and dusted cake tin and was leveled properly so as to leave a depression in the centre. Cake was baked at $180^{\circ} \mathrm{C}$ for 20 minutes. Cake was finally cooled on a cooling-rack.

Muffins: Flours (10g quinoa- $45 \mathrm{~g}$ rice- $45 \mathrm{~g}$ oats) with baking powder $(2 \mathrm{~g})$ were sifted (sieved) twice. Eggs $(150 \mathrm{~g})$ were beaten in a bowl. Vanilla essence $(3 \mathrm{ml})$ and powdered sugar $(100 \mathrm{~g})$ was added and mixed till the contents became very stiff. Melted butter $(30 \mathrm{~g})$ and refined oil $(40 \mathrm{~g})$ was added and mixed well with other ingredients. Enameled bowl containing beaten eggs was taken out from hot water. Flour was added gradually and gently mixed with other ingredients with a knife. Mixture was poured into prepared muffin tray. Muffins were baked at $200^{\circ} \mathrm{C}$ for 20 minutes.

Pies: Butter $(70 \mathrm{~g})$ and sugar $(35 \mathrm{~g})$ were creamed with hands and palms on flat surface. Flours $(10 \mathrm{~g}$ quinoa$45 \mathrm{~g}$ rice- $45 \mathrm{~g}$ oats) and baking powder $(3 \mathrm{~g})$ were added and mixed it with hands by rubbing with palm and made into dough. The dough was flattened with rolling pin to $1 / 4$ inch thickness. Rolled dough was placed on the apple pie moulds. Extra edges were cut using knife. Shaped dough was pricked with fork. Gluten free sponge cake (20g), chopped apple $(20 \mathrm{~g})$, sugar $(10 \mathrm{~g})$, cinnamon powder $(10 \mathrm{~g})$ and raisins $(5 \mathrm{~g})$ were mixed together for filling. $20 \mathrm{ml}$ of water was taken in a pan and cooked the mixture for $2-3$ minutes. The mixture was placed in pie tray and placed strips on top. Pies were baked at $200^{\circ} \mathrm{C}$ for 20 minutes.

Tarts: Butter $(67 \mathrm{~g})$ and sugar $(35 \mathrm{~g})$ were creamed together by spreading it on the flat surface. Flours $(10 \mathrm{~g}$ quinoa-45g rice-45g oats) and baking powder (2.5g) was mixed with fingers. Balls were made and kept for rest for $10-15$ minutes (Each ball had approximately $15 \mathrm{gm}$ weight).Balls were flattened with rolling pin 
and the shapes were cut with doughnut cutter. Flattened balls were placed in tart mould and pricked with fork. Extra batter was trimmed from sides of moulds. Tarts were baked in oven at $180^{\circ} \mathrm{C}$ for 20 minutes. After cooling, tarts were coated with chocolate sauce (20g) and filled with whipped cream $(20 \mathrm{~g})$, chopped mango (10g) and kiwi (10g).

Sensory evaluation: Quinoa based gluten free bakery products was processed for sensory evaluation immediately after development. The organoleptic characteristics of products were determined using a taste panel consisting of 10 judges who were familiar with the major sensory attributes of food products. The panelists were asked to evaluate the food products for appearance colour, texture, flavor and overall acceptability. Each day four samples having one control and three experimental samples were presented in identical containers coded with different numbers and served simultaneously. Each sample was repeated thrice during course of evaluation. The rating was done on 8 point hedonic rating scale (Larmond, 1970). The degree, to which a product was liked was expressed as liked extremely (8 points), liked very much (7 points), liked moderately (6 points), liked slightly ( 5 points), disliked slightly (4 points), disliked moderately (3 points), disliked very much (2 points), disliked extremely (1 point).The testing was conducted in Food laboratory of department of Food and Nutrition, College of Home Science, Punjab Agricultural University, Ludhiana.

Statistical analysis: The data was analyzed with the help of various statistical tools such as mean and standard error. To test the significant difference between the control and experimental samples, ANOVA, two tail $\mathrm{t}$ - test and Critical Difference was applied using SPSS 16 software.

\section{RESULTS AND DISCUSSION}

Chemical composition of roasted quinoa grains: Chemical composition of quinoa grains is shown in table 1 which clearly stated that roasted quinoa grain

Table 1. Chemical composition of roasted quinoa grains (per $100 \mathrm{~g}$ DM)

\begin{tabular}{ll}
\hline Crude protein $(\mathrm{g})$ & $8.61^{\mathrm{d}} \pm 0.07$ \\
Crude fat $(\mathrm{g})$ & $3.46^{\mathrm{d}} \pm 0.06$ \\
Carbohydrates $(\mathrm{g})$ & $80.18^{\mathrm{a}} \pm 1.11$ \\
Total Iron $(\mathrm{mg})$ & $4.20^{\mathrm{b}} \pm 0.06$ \\
Total Calcium $(\mathrm{g})$ & $53.33^{\mathrm{d}} \pm 0.33$ \\
Total Zinc $(\mathrm{mg})$ & $2.83^{\mathrm{a}} \pm 0.03$ \\
Magnesium $(\mathrm{mg})$ & $111.00^{\mathrm{d}} \pm 0.58$ \\
Energy (kcal) & 386 \\
Lysine (g/100g protein) & $4.87^{\mathrm{c}} \pm 0.18$ \\
Methionine g/100g protein) & $1.67^{\mathrm{a}} \pm 0.03$ \\
Tryptophan g/100g protein) & $0.59^{\mathrm{c}} \pm 0.04$ \\
\hline
\end{tabular}

Carbohydrate $=100-($ Minerals + Protein + Fat + Fibre $) ;$ Energy $=$ $($ Proteinx4) $+($ Carbohydratex4) $+($ Fatx9); Values are mean \pm $\mathrm{SD}$; Values are taken in triplicate was found to be rich in protein $(8.61 \pm 0.07)$ and low in fat $(3.46 \pm 0.06)$ based on $\mathrm{g} / 100 \mathrm{~g}$ on dry weight basis. Quinoa is considered to be a source of good quality protein due to its balanced amino acid composition. (Lysine is a dominant amino acid). Alvarez-Jubete et al (2009) stated the protein content in quinoa to be 14.5 percent on dry weight basis and the nitrogen to protein conversion factor used were 5.96 for quinoa seeds. Lipid content in amaranth and quinoa is between 2 and 3 times higher than in buckwheat and common cereals such as wheat and is 5.2 percent on dry weight basis in raw quinoa flour. Gamel et al (2004) stated that the protein quality can also be affected by processing. However, when processed under conditions that do not damage the availability of essential amino acids, protein quality of the pseudo cereals seeds is not negatively affected by processing. The seeds contained good amount of calcium (53.33 \pm $0.33)$, zinc $(2.83 \pm 0.03)$ and magnesium (111.00 \pm $0.58) \mathrm{mg} / 100 \mathrm{~g}$. Roasted quinoa grains were found to contain high amino acid profile i.e lysine $(4.87 \pm 0.18)$, methionine (1.67 \pm 0.03$)$ and tryptophan $(0.59 \pm 0.04)$. Valencia (2003) stated that the quinoa has a good balance of the amino acids that make up the protein. It is also a good complement for legumes, which are often low in methionine (Valencia 2003). So, the quinoa grains being rich in protein,essential amino acids and minerals may provide a good alternative for preparation of gluten free bakery products.

Sensory evaluation of developed products: Sensory evaluation of different quinoa based gluten free baked products is shown in Table 2.

Cookies: The results stated that the control sample of cookies was given scores by panel ranging from 7.5 to 7.6 for different quality attributes which were highest among all test samples. In case of appearance, colour and texture significant $(\mathrm{p} \leq 0.05)$ scores were gained by control (7.6 $\pm 0.22,7.5 \pm 0.26$ and $7.6 \pm 0.22)$ and least scores $(7.2 \pm 0.20,7.2 \pm 0.20$ and $7.0 \pm 0.25)$ were given to test sample supplemented with 5 percent roasted quinoa flour. Supplementation of roasted quinoa flour impaired the flavour of cookies possibly due to bitter taste of quinoa grains due to presence of saponins constituting the sapogenols, oleanolic acid, hederagenin and phytolaccagenic acid) which decreased the scores significantly $(\mathrm{p} \leq 0.05)$ from control $(7.5 \pm 0.26)$ to 15 percent level (7.2 \pm 0.29$)$.Addition of roasted quinoa flour was equally acceptable at 10 percent and 15 percent level for all parameters while 5 percent level of supplementation was found to be least acceptable. From overall acceptability ratings, it can be concluded that roasted quinoa flour can be supplemented in cookies upto 15 percent without affecting its sensory qualities. Lorenz and Coulter (1991) evaluated the performance of quinoa-wheat flour blends (5/95, 10/90, 20/80, 30/70) in cookies. Cookie spread and top grain scores decreased with increasing levels of quinoa flour 
Table 2. Sensory evaluation of gluten free bakery products using roasted quinoa flour.

\begin{tabular}{|c|c|c|c|c|c|}
\hline Gluten free bakery products & Appearance & Colour & Texture & Flavour & Overall Acceptability \\
\hline \multicolumn{6}{|l|}{ Cookies } \\
\hline Control & $7.6^{\mathrm{a}} \pm 0.22$ & $7.5^{\mathrm{a}} \pm 0.26$ & $7.6^{\mathrm{a}} \pm 0.22$ & $7.5^{\mathrm{a}} \pm 0.26$ & $7.54^{\mathrm{a}} \pm 0.23$ \\
\hline $5 \%$ & $7.2^{\mathrm{a}} \pm 0.20$ & $7.2^{\mathrm{a}} \pm 0.20$ & $7.0^{\mathrm{a}} \pm 0.25$ & $7.0^{\mathrm{a}} \pm 0.25$ & $7.04^{\mathrm{a}} \pm 0.20$ \\
\hline $10 \%$ & $7.4^{\mathrm{a}} \pm 0.16$ & $7.4^{\mathrm{a}} \pm 0.16$ & $7.6^{\mathrm{a}} \pm 0.16$ & $7.5^{\mathrm{a}} \pm 0.16$ & $7.46^{\mathrm{a}} \pm 0.15$ \\
\hline $15 \%$ & $7.2^{\mathrm{a}} \pm 0.29$ & $7.2^{\mathrm{a}} \pm 0.29$ & $7.3^{\mathrm{a}} \pm 0.30$ & $7.2^{\mathrm{a}} \pm 0.29$ & $7.2^{\mathrm{a}} \pm 0.27$ \\
\hline \multicolumn{6}{|l|}{ Cakes } \\
\hline Control & $7.5^{\mathrm{a}} \pm 0.22$ & $7.4^{\mathrm{a}} \pm 0.22$ & $7.1^{\mathrm{ab}} \pm 0.27$ & $7.3^{\mathrm{a}} \pm 0.26$ & $7.32^{\mathrm{a}} \pm 0.21$ \\
\hline $5 \%$ & $7.1^{\mathrm{a}} \pm 0.23$ & $7.1^{\mathrm{a}} \pm 0.23$ & $6.8^{\mathrm{ab}} \pm 0.20$ & $6.9^{\mathrm{a}} \pm 0.17$ & $7.0^{\mathrm{a}} \pm 0.16$ \\
\hline $10 \%$ & $7.5^{\mathrm{a}} \pm 0.16$ & $7.6^{\mathrm{a}} \pm 0.16$ & $7.6^{\mathrm{a}} \pm 0.16$ & $7.5^{\mathrm{a}} \pm 0.16$ & $7.54^{\mathrm{a}} \pm 0.15$ \\
\hline $15 \%$ & $7.0^{\mathrm{a}} \pm 0.29$ & $6.9^{\mathrm{a}} \pm 0.27$ & $6.7^{\mathrm{b}} \pm 0.26$ & $6.9^{\mathrm{a}} \pm 0.31$ & $6.8^{\mathrm{a}} \pm 0.24$ \\
\hline \multicolumn{6}{|l|}{ Muffins } \\
\hline Control & $7.1^{\mathrm{a}} \pm 0.17$ & $7.0^{\mathrm{a}} \pm 0.21$ & $6.8^{\mathrm{a}} \pm 0.20$ & $7.0^{\mathrm{a}} \pm 0.21$ & $7.0^{\mathrm{a}} \pm 0.18$ \\
\hline $5 \%$ & $7.0^{\mathrm{a}} \pm 0.14$ & $6.95^{\mathrm{a}} \pm 0.18$ & $6.9^{\mathrm{a}} \pm 0.27$ & $7.1^{\mathrm{a}} \pm 0.17$ & $7.02^{\mathrm{a}} \pm 0.12$ \\
\hline $10 \%$ & $7.4^{\mathrm{a}} \pm 0.22$ & $7.35^{\mathrm{a}} \pm 0.29$ & $7.2^{\mathrm{a}} \pm 0.29$ & $7.3^{\mathrm{a}} \pm 0.30$ & $7.32^{\mathrm{a}} \pm 0.26$ \\
\hline $15 \%$ & $7.1^{\mathrm{a}} \pm 0.17$ & $7.15^{\mathrm{a}} \pm 0.23$ & $6.95^{\mathrm{a}} \pm 0.26$ & $7.0^{\mathrm{a}} \pm 0.21$ & $7.08^{\mathrm{a}} \pm 0.19$ \\
\hline \multicolumn{6}{|l|}{ Pies } \\
\hline Control & $7.2^{\mathrm{a}} \pm 0.20$ & $7.2^{\mathrm{a}} \pm 0.20$ & $7.4^{\mathrm{a}} \pm 0.16$ & $7.2^{\mathrm{a}} \pm 0.13$ & $7.24^{\mathrm{a}} \pm 0.14$ \\
\hline $5 \%$ & $7.3^{\mathrm{a}} \pm 0.26$ & $7.1^{\mathrm{a}} \pm 0.23$ & $7.2^{\mathrm{a}} \pm 0.29$ & $7.2^{\mathrm{a}} \pm 0.24$ & $7.18^{\mathrm{a}} \pm 0.23$ \\
\hline $10 \%$ & $7.7^{\mathrm{a}} \pm 0.15$ & $7.7^{\mathrm{a}} \pm 0.15$ & $7.9^{\mathrm{a}} \pm 0.10$ & $7.8^{\mathrm{a}} \pm 0.13$ & $7.78^{\mathrm{a}} \pm 0.10$ \\
\hline $15 \%$ & $7.5^{\mathrm{a}} \pm 0.16$ & $7.3^{\mathrm{a}} \pm 0.15$ & $7.5^{\mathrm{a}} \pm 0.22$ & $7.5^{\mathrm{a}} \pm 0.22$ & $7.48^{\mathrm{a}} \pm 0.16$ \\
\hline \multicolumn{6}{|l|}{ Tarts } \\
\hline Control & $7.5^{\mathrm{a}} \pm 0.22$ & $7.5^{\mathrm{a}} \pm 0.22$ & $7.4^{\mathrm{a}} \pm 0.22$ & $7.4^{\mathrm{a}} \pm 0.16$ & $7.46^{\mathrm{a}} \pm 0.14$ \\
\hline $5 \%$ & $7.2^{\mathrm{a}} \pm 0.20$ & $7.3^{\mathrm{a}} \pm 0.21$ & $7.1^{\mathrm{a}} \pm 0.23$ & $7.0^{\mathrm{a}} \pm 0.25$ & $7.1^{\mathrm{a}} \pm 0.20$ \\
\hline $10 \%$ & $7.6^{\mathrm{a}} \pm 0.16$ & $7.6^{\mathrm{a}} \pm 0.16$ & $7.5^{\mathrm{a}} \pm 0.16$ & $7.5^{\mathrm{a}} \pm 0.16$ & $7.56^{\mathrm{a}} \pm 0.15$ \\
\hline $15 \%$ & $7.3^{\mathrm{a}} \pm 0.30$ & $7.2^{\mathrm{a}} \pm 0.32$ & $7.1^{\mathrm{a}} \pm 0.27$ & $7.1^{\mathrm{a}} \pm 0.31$ & $7.14^{\mathrm{a}} \pm 0.29$ \\
\hline
\end{tabular}

Values are mean $\pm \mathrm{SD}$; Values are taken in triplicate; Alphabets with different superscripts shows significant difference at $5 \%$ level of significance; Scores are out of nine on 9 point hedonic scale (9- Excellent, 8- Extremely good, 7- Very good, 6- Moderately good, 5- Good, 4- Fair, 3- Very fair, 2- Poor, 1- Very poor).

blended with high-spread cookie flour. Flavour improved up to 20 percent quinoa flour in the blend. Cookie spread and cookie appearance was improved with a quinoa/low-spread flour blend by using 2 percent lecithin. Arendt et al (2002) studied the effects of rice, corn, soya, millet, buckwheat and potato starch in combination with different fat sources on the formulation of gluten free biscuits. Rice, corn, potato and soya with high fat powders produced biscuit doughs, which were sheetable and biscuits of comparable quality to wheat biscuits.

Bhathal (2016) developed the cookies by using 100 percent quinoa in test sample and 100 percent refined flour in control sample. The results states that the test sample had higher scores than the control in all the parameters of sensory attributes. The mean scores of overall acceptability of test sample i.e. 7.94 which were significantly higher than the control cookies i.e. 7.28 .

Cakes: The perusal of data (Table 2) showed that best scores were obtained by test sample supplemented with 10 percent of roasted quinoa flour for all organoleptic attributes. In case of appearance and colour significant scores $(\mathrm{p} \leq 0.05)$ were obtained by the control as well as test samples supplemented at 5,10 and 15 percent levels. In case of texture, the scores of control and 5 percent level of supplementation showed non- significant difference but 15 percent was found significantly different from all treatments and obtained the least scores. Flavour of cakes was not altered by supplementation of roasted quinoa flour in all treatments. In case of flavour, 10 percent level of roasted quinoa flour supplementation achieved highest (7.5 \pm 0.16$)$ scores among all treatments after control (7.3 \pm 0.26$)$. Level of 15 percent $(6.9 \pm 0.31)$ was least liked by the judges. Among all the treatments overall acceptability was highest for 10 percent level with $7.54 \pm 0.15$ scores followed by 5 and 15 percent with $7.0 \pm 0.16$ and $6.8 \pm 0.24$ scores. Lorenz and Coulter (1991) evaluated the performance of quinoa-wheat flour blends $(5 / 95$, $10 / 90,20 / 80,30 / 70)$ in cakes. Cake quality was acceptable with 5 and 10 percent of quinoa flour. Cake grain became more open and the texture less silky as the level of quinoa substitution increased. Cake taste improved with either 5 or 10 percent quinoa flour in the blend. Gallagher et al (2003) found the results for the loaf volume, bake loss (\%) and colour of the baked breads. The replacement of potato starch by each of the pseudo cereal flours had a variable effect on loaf volume. Bake loss differed slightly between the gluten free control and the pseudo cereal-containing gluten free breads. However, the differences were not significant. In relation to the crust colour of the baked breads, the pseudo cereal-containing gluten free breads were 
Sukhmandeep Kaur and Navjot Kaur / J. Appl. \& Nat. Sci. 9 (4): 2449 - 2455 (2017)

Table 3. Calculated nutritive value of developed gluten free bakery products (per 100 grams).

\begin{tabular}{lccccc}
\hline Parameter & Cookies & Cakes & Muffins & Pies & Tarts \\
\hline Energy (Kcal) & 451.52 & 403.75 & 373.62 & 485.28 & 484.84 \\
Protein (g) & 4.2 & 7.35 & 8.4 & 5.6 & 5.95 \\
Fat (g) & 24.94 & 19.6 & 21.54 & 29.2 & 29 \\
Carbohydrate (g) & 52.54 & 49.48 & 36.54 & 50.02 & 50.01 \\
Iron (mg) & 1.65 & 1.57 & 1.58 & 1.73 & 1.69 \\
Calcium (mg) & 29.22 & 31.16 & 34.84 & 23.33 & 23.04 \\
Magnesium (mg) & 31.42 & 19.6 & 14.82 & 33.41 & 32.73 \\
Zinc (mg) & 0.51 & 0.32 & 0.24 & 0.54 & 0.53 \\
\hline
\end{tabular}

Acceptable level: $10 \%$ in all products.

significantly darker as compared with the gluten free control. The darkening of the crust colour brought about by the replacement of potato starch by pseudo cereal flour is desirable as gluten free breads tend to have a lighter crust colour than white wheat breads which sometimes appear artificial.

Muffins: On perusal of data (Table 2) it was found that supplementation of roasted quinoa flour at 10 and 15 percent improved the appearance of muffins (7.4 \pm 0.22 and $7.1 \pm 0.17)$. But at 5 percent level, it decreased $(7.0 \pm 0.14)$. No treatment was found significantly different when compared with control. Same score was obtained by control and 15 percent level $(7.1 \pm 0.17)$ of supplementation with quinoa flour in muffins. In case of colour 10 percent level of supplementation got highest scores $(7.35 \pm 0.29)$ followed by 15 percent $(7.15 \pm 0.23)$ and control $(7.0 \pm 0.21)$. Least score was obtained by test sample supplemented with 5 percent of roasted quinoa flour. A non significant difference was found in mean scores of control and all treatments for texture ranged from 6.8 (control) to 7.2 $(10 \%)$. For flavour, highest scores $(7.3 \pm 0.30)$ was attained by 10 percent level of supplementation of roasted quinoa flour followed by 5 percent $(7.1 \pm 0.17)$ with non-significant difference. The least scores were computed for control and 15 percent level of supplementation (7.0 \pm 0.21$)$. Overall acceptability was obtained at 10 percent level of supplementation $(7.32 \pm 0.26)$ followed by 15 percent $(7.08 \pm 0.19)$ and 5 percent (7.02 \pm 0.12$)$.Castillo et al (2009) formulated gluten free food for people with celiac disease based on quinoa, rice and corn flours and starches. The obtained products were pancakes, scones, precooked pizza and bread which were analyzed for their chemical composition (protein, fat, fiber, moisture, ash and carbohydrates). In pancakes and scones an increase of protein content was observed i.e. 88 and 198 percent respectively. However, all products have chemical scores higher to 100 . Overall, the formulated products provide good quality proteins and have good textural characteristics and adequate percentages of acceptability to be used in the feeding of celiac patients.

Pies: The scores of pies revealed (Table 2) that test sample supplemented with 10 percent level of supplementation of roasted quinoa flour was scored as extremely good. In case of appearance 10 percent level of supplementation scored highest $(7.7 \pm 0.15)$ scores followed by 15 percent $(7.5 \pm 0.16)$ and 5 percent $(7.3 \pm 0.26)$. None of the treatment was found significantly different when compared with control which was given $7.2 \pm 0.20$ scores. In case of colour 10 percent level of supplementation was awarded as 'liked very much' followed by 15 percent and 5 percent level of supplementation. Crunchiness of roasted quinoa grains which improved the texture of pies was responsible for highest scores $(7.9 \pm 0.10)$ achieved by 10 percent level of substitution of roasted quinoa flour followed by 15 percent and control. Five percent level of supplementation was given minimum mean scores (7.2 \pm 0.29$)$. Similar results were found in case of flavour in which highest scores was achieved by 10 percent $(7.8 \pm 0.13)$ followed by 15 percent and 5 percent level of supplementation. Overall acceptability revealed that test sample supplemented with 10 percent level of roasted quinoa flour was found to be highly acceptable amongst all the test samples of gluten free bakery products as well as control samples. So quinoa flour can be supplemented in pies upto 10 percent level without affecting sensory attributes. Oshodi et al (1999) used the quinoa flour, in combination with wheat flour or corn meal, in making biscuits, bread and processed food. The quinoa seed flour has good gelation property, water-absorption capacity, emulsion capacity and stability. Alvarez et al (2010) assessed the nutritional properties and baking characteristics of amaranth, quinoa and buckwheat. They found that the replacement of potato starch with a pseudocereal flour resulted in gluten free breads with an increased content of important nutrients such as protein, fiber, calcium, iron and vitamin E. The resulting breads also had a significantly higher content of polyphenol compounds and their in vitro antioxidant activity was increased.

Tarts: The results (Table 2) stated that the test sample supplemented with 10 percent roasted quinoa flour was given scores ranging from 7.5 to 7.6 for different quality attributes which were highest among all test samples. In case of appearance, colour and taste significant $(p \leq 0.05)$ scores $(7.6 \pm 0.16)$ were gained by test sample supplemented with 10 percent roasted quinoa flour. In case of texture 10 percent level of supplementation achieved significantly $(\mathrm{p} \leq 0.05)$ highest scores (7.5 \pm 0.16$)$ among all the treatments after control 
(7.4 \pm 0.22$)$. Among all the treatments overall acceptability was highest for 10 percent level with $7.56 \pm 0.15$ scores followed by 15 percent and 5 percent with $7.14 \pm 0.29$ and $7.1 \pm 0.20$ scores with good flavour, texture, colour and appearance. Michala et al (2009) investigated the rheological properties of doughs prepared from wheat flour with buckwheat and quinoa flour addition $(2.5$ mass $\%, 5.0$ mass $\%, 7.5$ mass $\%$ and 10 mass \%) using a farinograph and compared with those of standard dough (without addition of pseudocereals). Dough stability showed a linear decrease with the increasing content of pseudocereals. Dough containing quinoa flour was more stable than those with buckwheat flour addition. Dough growth time was not affected in the case of quinoa flour addition. From the comparison of the studied characteristics it can be concluded that an addition of lower amounts of quinoa (up to 5.0 mass \%) to wheat flour will not significantly impair rheological properties of the dough but provides for enhanced nutritional value of the prepared bakery products.

Data from the Table 2 showed that test products made from rice and oats flour supplemented with quinoa flour such as cakes, pies and tarts were found to be highly acceptable. All these products were liked very much with an overall acceptability mean scores for cakes (7.54 \pm 0.15$)$, pies $(7.78 \pm 0.10)$ and tarts (7.56 \pm 0.15$)$. The best score for appearance and colour was obtained by test pies i.e. $7.7 \pm 0.15$ and $7.7 \pm 0.15$ respectively. The best score for texture and flavour was also obtained by test pies. The test cookies and muffins were also found to be acceptable with the overall acceptability of $7.46 \pm 0.15$ and $7.32 \pm 0.26$.

\section{Conclusion}

With increase in the level of roasted quinoa flour supplementation in all preparations, the overall acceptability decreased. The products having 10 percent quinoa flour were found to be highly acceptable by the semitrained panel of judges. Among those, test products made from rice and oats flour supplemented with quinoa flour such as cakes, pies and tarts were found to be highly acceptable. These products were liked very much with an overall acceptability mean score for cakes $(7.54 \pm 0.15)$, pies $(7.78 \pm 0.10)$ and tarts (7.56 \pm 0.15$)$. The best score for appearance and colour was obtained by test pies $(7.7 \pm 0.15)$ and $(7.7 \pm 0.15)$ respectively. The test cookies and muffins were also found to be acceptable with the overall acceptability of $7.46 \pm 0.15$ and $7.32 \pm 0.26$. On the basis of the results, it may be concluded that supplemented products with 10 percent level of roasted quinoa flour can be successfully prepared with high nutritional value and without imposing a negative impact on sensory attributes, which can prove a boon to celiac patients.

\section{REFERENCES}

Alvarez-Jubete L, Arendt E K and Gallagher E (2009). Nutritive value and chemical composition

of pseudocereals as gluten-free ingredients. Int J Food Sci and Nutr60: 240-57.

Alvarez J L, Arendt E K and Gallagher E (2010). Nutritive value and chemical composition of pseudocereals as gluten free ingredients. Int $J$ Food Sci Nutr., 60: $240-57$

AOAC (2000) Official Method of Analysis Association of Official Analytical Chemist, $17^{\text {th }}$ ed. Washington DC

Arendt E K, O Brien C M, Schober T, Gormley T R and Gallagher E (2002) Development of gluten free cereal products. Farm Food 12: 21-27.

Bhathal S K (2016) Development and Nutritional evaluation of Quinoa (Chenopodium quinoa) based gluten free products. M.Sc. thesis, Punjab Agricultural University, Ludhiana, India.

Booth V H (1971) Problems in determination of FDNB available lysine. $J$ Sci Food Agric 22:658-66.

Carpenter K J (1960) The estimation of available lysine in animal protein foods. $J$ Biochem 77: 604-10.

Castillo V D, Lescano G and Armada M (2009) Foods formulation for people with celiac disease based on quinoa (Chenopodium quinoa), cereal flours and starches mixtures. Arch LatinoamNutr59: 332-36.

Concon J M (1975) Rapid and simple method for determination of tryptophan in cereal grains. Anal Biochem67:206.

Drzewiecki J, Delgado-Licon E, Haruenkit R, Pawelzik E, Martin-Belloso O and Park Y S (2003) Identification and differences of total proteins and their soluble fractions in some pseudocereals based on electrophoretic patterns. J Agri Food Chem51: 7798-804.

Gallagher E, Gormley T R and Arendt E K (2003) Crust and crumb characteristics of gluten free breads. $J$ Food Eng56: 153-61.

Galvez A V, Miranda M, Vergara J, Uribe E, Puente L and Martinez E A (2010) Nutrition facts and functional potential of quinoa (Chenopodium quinoaWilld.), an ancient Andean grain: A review. J Sci and Food Agric90: 2541-47.

Gamel T H, Linssen J P, Alink G M, Mossallem A S and Shekib L A (2004) Nutritional study of raw and popped seed proteins of Amaranth caudatus L. abd Amaranth cruentus L. J Sci Food Agri 84: 1153-58.

Horn M J, Jones D B and Blum A E (1946) Colorimetric determination of methionine in proteins and foods. $J$ BiolChem 166: 313-20.

Jacobsen S E (2003) The worldwide potential for quinoa (Chenopodium quinoaWilld.). Food Rev Int 19: 167-77.

Larmond E (1970) Methods of sensory evaluation of food. Can Deptt Agric Pubs: 1284-90.

Lindsey W L and Norwell M A (1969) A new DPTA-TEA soil test for zinc and iron. AgronAbst61: 84 .

Lorenz K and Coulter L (1991) Quinoa flour in baked products. PlantFood Hum Nutr41: 213-223.

Michala J, Lucia M and Alexander D (2009) Rheological properties of doughs with buckwheat and quinoa additives. Chemical Papers63: 738-41.

Moreno M L, Comino I and Sousa C (2014) Alternative grains as potential raw material for gluten free food 
Sukhmandeep Kaur and Navjot Kaur / J. Appl. \& Nat. Sci. 9 (4): 2449 - 2455 (2017)

development in the diet of celiac and gluten-sensitive patients. Austin J Nutri Food Sci2: 1- 9.

Oshodi A A, Ogungbenle H N and Oladimeji M O (1999)

Chemical composition, nutritionally valuable minerals and functional properties of benniseed (Sesamumradiatum), pearl millet (Pennisetumtyphoides) and quinoa (Chenopodium quinoa) flours. Int $J$ Food Sci Nutr50: 325-31.
Rashid M, Butzner D, Burrows V, Zarkadas M, Case S, Molloy M, Warren R, Pulido O and Switzer C (2007) Consumption of pure oats by individuals with celiac disease. Can J Gastroenterol, 21: 649-51.

Ruales J and Nair B M (1994) Properties of Starch and Dietary Fibre in Raw and Processed Quinoa (Chenopodium quinoa, Willd) Seeds. Plant Foods for Human Nutrition, 45: 223-46. 